\title{
The relation between multi-cultural group work and the integration of home and international students
}

\author{
Gita Sedghi ${ }^{1}$ \& Elisabeth Rushworth ${ }^{2 *}$ \\ ${ }^{1}$ Department of Chemistry, ${ }^{2}$ Central Teaching Laboratory, The University of Liverpool, UK
}

*Corresponding author: lisrush@liverpool.ac.uk

Keywords: Internationalisation; Integration; Group work; Home; international

\begin{abstract}
Group working skills are essential attributes for graduates in higher education, and are highly valued by prospective employers of home and international students. With increasing numbers of international students, with different social, cultural, and academic backgrounds, there is an opportunity to evaluate the students' perceptions of, and the potential benefits for, student integration in multi-cultural group work. The research measured students' attitudes towards multicultural group activities compared with different aspects of group work in general. The opinions of students in two departments, Chemistry and Geography \& Planning, towards multi-cultural group work were generally positive, although international students had a better perception of the benefits, and were more likely to selfassign themselves to mixed groups, than home students. International students found the cognitive benefits of culturally mixed groups, and their effect on enhancing integration, more favourable than home students. Conversely, home students have a better overall perception of the benefits of the emotional aspects of the group work, how they will manage the assignment, the development of interpersonal skills, and group assessment than international students. In general, the results imply that tutors should deliberately assign students to multi-culturally mixed groups to encourage integration, and that the academic tasks for the assignments should be developed sensitively to encourage engagement with both cohorts of students.
\end{abstract}

\section{Introduction}

There are increasing numbers of international students choosing undergraduate study in the UK (HESA, 2015; UKCISA, 2015), including the University of Liverpool, with more than 7000 international students on campus. International students choose study abroad to gain international experience, including improving their employability, language skills, the availability of subjects in demand in their home countries, and the personal benefits of increased freedom in the decision-making processes such as where they live, and the opportunity to pursue their own interests and hobbies (British Council, 2012, 2015b). They choose which country and institution by the reputation of the institution, the quality of the course, the international recognition of their final qualification, and on-campus facilities (British Council, 2015b). International students also bring benefits to the university campus;
"they bring diversity to campus life and enhance the student experience for 'home' students; they support the provision of certain subjects, particularly at postgraduate level; and they provide a valuable source of income to universities and to local economies via expenditure on and off campus"

(UUK, 2014).

Although enhancing integration and interaction between home and international students can be challenging (Popov et al., 2012; UUK, 2014; Vitaliy et al., 2012), recent work has shown that 
The relation between multi-cultural group work and the integration of home and international students

peer support can improve social integration which in turn supports academic integration (Willis \& Sedghi, 2014). Group working skills are essential attributes for University of Liverpool graduates, and are increasingly highly valued by prospective employers of students internationally (British Council, 2015a, 2015c; UUK, 2014). Group work assignments provide potential opportunities for improving student integration and developing desirable group working skills. They also provide us with the opportunity to evaluate the students' perceptions of, and the potential benefits for, student integration in multi-cultural group work.

\section{Rational for the integration of home and international students}

What does the term "internationalisation" mean in higher education? There are several definitions of internationalisation; however, one of the most commonly used defines internationalisation at the institutional level as "the process of integrating an international, intercultural or global dimension into the purpose, functions or delivery of postsecondary education" (Knight, 2004). This definition brings intercultural activities together with the terms "internationalisation" and "globalisation", which suggests that the three terms are not separable. Internationalisation and globalisation are not independent of intercultural activities. The relationship between cultures is an important part of every internationalised and globalised institution. Internationalisation in higher education can be interpreted as providing an inclusive teaching and learning environment for both home and international students. It has a worldwide impact which is about relating to different cultures, nations and countries and is about both home and international students (Knight, 2004).

Ennew and Greenway (2012) express the importance of working in a globalised and internationalised higher education institution with people from different cultures and backgrounds, as higher education institutions provide students with the opportunity to participate in intercultural academic activities in order to prepare them for international collaboration with future partners.
"Internationalising has positive impacts on the quality of teaching and learning. It offers the opportunity to contribute to globally significant research agendas and the opportunity to work with globally significant partners (Ennew \& Greenway, 2012)."

However, the increased number of international students on a university campus does not necessarily result in an increased understanding of cultural diversity. As Kramsch (2002) identified, internationalisation in the home country is achieved 'through internationalising the curriculum and providing intercultural activities on campus. Tinto (1975) also suggests that "Both academic and social integration is needed for students to perform well academically". Academic integration requires students to adapt to the teaching and learning system, and to know and enjoy the programme of study. Social integration requires students to communicate with staff and their peers in an academic environment and get involved in extracurricular activities. Other studies confirm Tinto's findings (Mannan, 2007; Rienties et al, 2012) and show a compensatory relationship between academic and social integration in higher education. The Baker and Siryk theory suggests that "There are four concepts in academic integration: academic, social, personal \& emotional adjustment and attachment. These are positively related with study performance." (Baker \& Siryk, 1999). Consequently, as suggested by Mannan (2007), institutions should develop strategic policies for the whole institution, as well as departments, subjects and years of studies.

\section{Group working as a strategy to integrate home and international students}

The increasing number of international students in higher education has created the need to find new ways to accommodate the academic and social requirements of both home and international students. There are a number of strategies employed in higher education to enhance integration of home and international students including peer support (Liou-Mark et al, 2010; Willis \& Sedghi, 2014), language support (Baohua \& Huizhong, 2012), and collaborative learning (Marjan \& Seyed Mohammad, 2011). Collaborative learning refers to students working in groups to 
complete a common task and to reach a certain goal (Marjan \& Seyed Mohammad, 2011). When compared to competitive and individualistic efforts, collaborative learning typically results in higher achievement and greater productivity, more caring, supportive, and committed relationships, and greater psychological health, social competence, and self-esteem (Marjan \& Seyed Mohammad, 2011).

The success of group work activities, however, is influenced by how the students perceive the value of both social and academic aspects of the activity (Wosnitza \& Volet, 2012). Where the group work activity is given a clear introduction and purpose the students were themselves able to identify the value of the activity (Kriflic \& Mullan, 2007), and were able to develop their own goals for success more effectively (Wosnitza \& Volet, 2012). In addition, groups demonstrate greater success where students are familiar with other members of the group; they show improvement during longer group work activities (Kimmel \& Volet, 2010), and in groups where students had previously worked together (Kimmel \& Volet, 2010; Wosnitza \& Volet, 2009). Although group size is seen as an important factor in successful group working, this is seen as less important than the academic support provided for students to understand the aim and structure of the group work (Kimmel \& Volet, 2010) and providing timely access to group work discussion (Bentley \& Warwick, 2013; Summers \& Volet, 2010). Recognition of individual contribution during assessment by providing an evaluation tool to identify individual contributions to group work is also a significant contributor to group success (Bentley \& Warwick, 2013). Summer and Volet (2008) indicate that forcing students to work in diverse groups, without providing appropriate support and training to raise their understanding of working in diverse groups, increases the negative attitude of students towards the group work. Consequently, providing appropriate support during the group work activities, and using appropriate terminology during the group selection process, may be very important to the success of the group work.

Diversity is a characteristic of every globalised and internationalised institution including higher education. Diversity is not only the diverse groups of home and international students but also the variety in academic skills, intellectual abilities, gender, disability, religious, language, etc. (Eva \& Roger, 2012). "Responding to the diversity of international students and responding to the diversity of home students are in fact not two agendas but one" (Jones \& Brown, 2007). There are mixed arguments about the benefits of working in culturally diverse groups and the influence of cultural diversity on group outcome. Umans (2011) suggests that group processes affect the group outcome, and cultural diversity has a negative influence on group outcome. In addition, Watson et al. (1998) suggests the long term positive outcome of working in heterogeneously cultural groups. However, whether the cultural diversity results in a positive or negative outcome at the time, it is obvious that many higher education graduates will work in international groups in their future professions.

Chickering and Gamson (1999) identify "Seven principles for good practice in undergraduate education" and suggest that having students with diverse talents and ways of learning at an institution is indicative of good practice in higher education. The challenges of working in complex groups when this principle is applied to a group work situation are, however, unavoidable. Nonetheless, Vitaliy et al. (2012) indicate that although challenges in both mono-cultural and multicultural groups with diversity elements are inevitable, it seems beneficial to try to overcome the shortcomings of multicultural groups and concentrate on the advantages of working with people from different cultures and backgrounds. Chickering and Gamson (1989) also suggest that as students have different abilities and talents, they could be pushed to learn new things by providing them with opportunities to learn in new ways and to work with new people.

Coser's (1975) "Complex social structures" theory identifies that situations in which a person experiences unfamiliar people, relationships and expectations, drive the development of that structure. Coser (1975) suggests that the challenges of being in an unfamiliar situation lead to cognitive growth and deep understanding of social relationships. Gurin et al. (2002) relates 
The relation between multi-cultural group work and the integration of home and international students

Coser's theory to the learning in higher education when unpredictable situations enhance students' modes of thoughts. Consequently, students in a diverse group need to make an extra effort to identify unknowns and adjust to unfamiliar conditions which results in them learning from each other (Gurin, et al, 2002).

This study focuses on the student perceptions of culturally mixed group work on the integration of home and international students in modules from The School of Physical Sciences and The School of Environmental Sciences. Summers and Volet (2008) studied the change of attitudes of business students towards culturally mixed group work assignments at different stages of their undergraduate studies while progressing from first to third year studies. Our study complements this research by looking into students' attitude towards culturally mixed group work across different scientific disciplines and comparing those results to the students' perceptions of general group work skills.

\section{Research Method}

\section{Procedure for data collection and analysis}

Because of the large number of students in the modules used for the study, and the wide remit of this research question, a questionnaire was selected to collect the data so that we could assess the student responses quantitatively. In order to ensure a high return rate for questionnaires, they were delivered and responded to during class time. To examine multi-cultural group work activities a questionnaire, combining a specific tool used in several previously published research projects, the "Contextualised-SAGA instrument" (Volet, 2001), and our own questions was provided to collect the data.

The Contextualised SAGA instrument is a task-context sensitive questionnaire suitable for measuring changes in the appraisals by the students over the duration of a group assignment (Kimmel \& Volet, 2012; Volet, 2001). It records the students' responses to six different sections designed to measure students' appraisals of group assignments: Cognitive Benefits, Motivational Influence, Group Assessment, Affect, Management, and
Interpersonal. Each section has a five item scale with student responses based on a combined conceptual and psychometric analysis based on Rasch modelling (Andrich, 1978; Kimmel \& Volet, 2012). In addition, it also includes a section, Cultural Mix, to measure the response to culturally mixed group work. The level of agreement with each item was measured on a four point Likert scale; Strongly disagree (1), disagree (2), agree (3), strongly agree (4). The means of the responses, calculated from the Likert scale before and after the group work, provides data to critique the student responses to different aspects of a multi-cultural group work.

In addition to the SAGA questionnaire, a pretask questionnaire also asked students about their previous experience in culturally mixed and non-mixed group work, their multicultural social, study, and work experience, and their opinion of their English language competency. Ethical consent for the data collection using these methods was obtained from the University of Liverpool.

\section{Choice of modules}

Modules were chosen from the School of Environmental Sciences and the School of Physical Sciences; Chem245 (Preparative chemistry: synthesis and characterisation), Chem311 (Inorganic chemistry III), and ENVS238 (Soils, slopes and the environment). They were selected for this study as all utilise group work activities for part of the module assessment, and represent a range of class sizes, subject disciplines, duration of group work, assessment strategies, and ratios of home to international students. The cohorts engaged in the modules comprised students from the UK and the EU which are both classed as home students, and international students from Xi'an Jiaotong-Liverpool University (XJTLU) (a partner university to the University of Liverpool in China), Science Without Borders (SWB) (a Brazilian government scholarship programme), and other international students. The groups of students in the modules were deliberately set to mix home and international students where possible.

CHEM245 is a second year core module which took place in semester one for 10 weeks. The group work is a combination of practical 
laboratory activities and workshops. The aim of the group work is to encourage students to discuss chemistry together in both labs and workshops. Students also perform a task on PeerWise (Hardy et al., 2014; Nicol, 2007), which is a learning tool allowing students to design their own questions and answers to peers' questions. The cohorts have different scientific backgrounds because the XJTLU students enter directly onto their second year studies in Liverpool. The XJTLU students have different experiences in their studies compared with our home students, especially in practical courses. The module leader of the course assigns 5-6 students to each group, ideally mixed groups of home and international students, although this is not always possible as majority of our students are British. The group work is a combination of tasks from both in and outside the classroom. The group work requires three submissions of work and comprises $10 \%$ of the overall module mark.

CHEM 311 is a core chemistry module on both BSc and masters programmes. The aim of the activity was for groups of approximately ten students, from a multinational background (XJTLU included), to develop a webpage on the applications of superconductors or semiconductors. Groups were purposely set to allow a mix of varying abilities and nationalities. The activity took place over two sessions of one hour each that were one week apart. The first session was to gain a brief overview of the task, divide the workload amongst the group and do some initial research. They were then expected to collaborate outside the classroom, either online or using "Scoop It!" to produce their webpage. The second session was to allow three-minute presentations of the "Scoop It" pages from each group. The links to the pages were collated on a shared wiki within the module VITAL page. The activity was not assessed as it was the first year that it was introduced.

ENVS238 is a second year optional module which took place in semester 2 for 12 weeks. The group work is a combination of field and practical laboratory activities. The cohort had differing scientific backgrounds because the XJTLU and SWB students start in year two at The University of Liverpool and so have different modules in their previous university experience compared to those students, either home or international, who start in year one. The activity involved an introductory lecture emphasising the importance of working in a multidisciplinary and multinational group and a combined field and lab project was completed with this mixed group over the whole semester. The group project is $60 \%$ of the overall module mark, $20 \%$ of which is an individual contribution and $40 \%$ is a group contribution.

All group assignments in this study provided a detailed introduction to the group work activity, and guidance about the requirements of group working, in order to enhance students' understanding and purpose of the activity. Also, where the group assignments took place over the whole term (CHEM245 and ENVS238), students were given guidance about the value of the group work.

\section{Questionnaire completion}

The numbers of students completing the before and after questionnaires were different in each module because students are allowed to leave or join the module up to three weeks into the start of the course, and in some cases the students did not attend the classes when the questionnaires were completed (Table1).

Where questionnaires were partially or incorrectly completed, the individual questions that were unanswered, or were incorrectly answered (i.e. two responses for one question), were removed from the data base. This resulted in a usable response to the questionnaires of between $58 \%$ and $92 \%$ (Table 2).

The data analysis used in the results and discussion includes that from both complete and incomplete questionnaires.

Questionnaires with some incomplete questions were not removed in their entirety where the lack of completion of one question does not affect the response to any other questions, and so does not affect the integrity of the given answers. The responses to multiple questions were combined where they are investigating the same question posed differently. The data is reported in the results using $\mathrm{N}=$ the number of responses, $\mathrm{M}=$ the mean Likert scale response and $S D=$ the standard deviation of the responses. 
The relation between multi-cultural group work and the integration of home and international students

\begin{tabular}{|llll|}
\hline Module code & CHEM245 & CHEM311 & ENVS238 \\
\hline Student numbers at the start of the group work & 97 & 82 & 19 \\
\hline Ratio of home : international students & $82: 15$ & $59: 23$ & $12: 7$ \\
\hline Student numbers at the end of the group work & 78 & 68 & 23 \\
\hline Ratio home : international students & $63: 13$ & $45: 22$ & $14: 9$ \\
\hline
\end{tabular}

Table 1 Student numbers completing questionnaires before and after group work for each module.

\begin{tabular}{|lllllll|}
\hline & $\begin{array}{l}\text { CHEM245 } \\
\text { Before }\end{array}$ & $\begin{array}{l}\text { CHEM245 } \\
\text { After }\end{array}$ & $\begin{array}{l}\text { CHEM311 } \\
\text { Before }\end{array}$ & $\begin{array}{l}\text { CHEM311 } \\
\text { After }\end{array}$ & $\begin{array}{l}\text { ENVS238 } \\
\text { Before }\end{array}$ & $\begin{array}{l}\text { ENVS238 } \\
\text { After }\end{array}$ \\
\hline $\begin{array}{l}\text { International } \\
\text { Students }\end{array}$ & $73 \%$ & $92 \%$ & $74 \%$ & $82 \%$ & $86 \%$ & $89 \%$ \\
\hline $\begin{array}{l}\text { Home } \\
\text { Students }\end{array}$ & $78 \%$ & $66 \%$ & $58 \%$ & $63 \%$ & $83 \%$ & $86 \%$ \\
\hline
\end{tabular}

Table 2 Percentage of correctly completed answers in the before and after questionnaires, listed by module and international and home students.

\section{Results}

In this section we report a statistical analysis of our results. Readers interested in the outcomes may wish to go directly to the discussion section.

\section{Multi-cultural experience from the pre-task questionnaire}

All students were asked if they had had previous experience of studying or working in a different country and if they regularly socialise with friends from other cultures (Figure 1). Although international students are more likely to have previous experience of studying or working in a different country compared to home students, they are much less likely to regularly socialise with friends from other cultures.

The non-native English speakers also rated their own language skills, with the majority of international students rating them as very strong to average (Figure 2).

Fifteen home students also identified themselves as non-native English speakers, with predominantly very strong language skills.

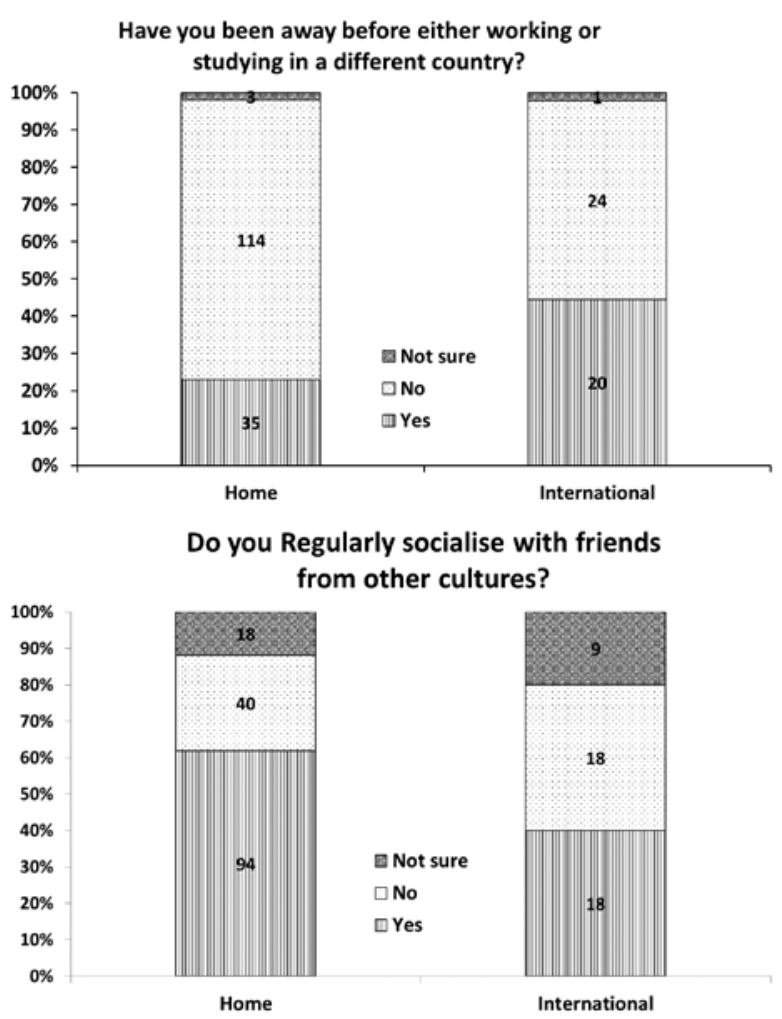

Figure 1. Home and international student's previous experience and preference for multicultural socialising and working. International students are more likely to have previous experience

of studying or working in a different country compared to home students, but are much less likely to regularly socialise with friends from other cultures than home students. 
The relation between multi-cultural group work and the integration of home and international students

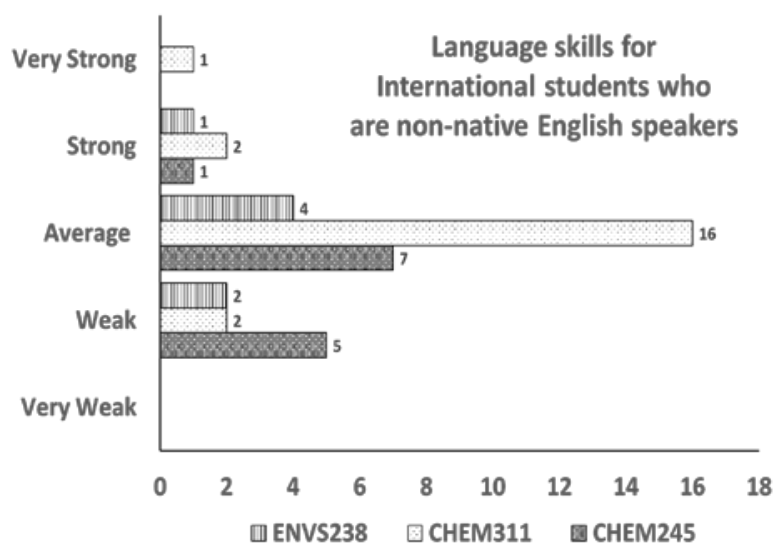

Figure 2 International students rate their language skills, with the majority rating them as very strong to average.

\section{Multi-cultural experience from the SAGA questionnaire}

Our research questions aimed at students' perceptions of mixed group work asked about their preference, for working in multi-culturally mixed groups, if they would self-select into mixed groups, or if they preferred the tutor to assign them. Before the group work took place, both home students $(\mathrm{N}=709, \mathrm{M}=2.73, \mathrm{SD}=$ $0.66)$ and international students $(N=214, M=$ $2.93, \mathrm{SD}=0.58$ ) were generally agreed that tutors should systematically mix home and international students during group work. Afterwards, the opinions of the international students were slightly less positive $(N=212, M$ $=2.88, \mathrm{SD}=0.60)$, but the home students were slightly more positive about the experience ( $\mathrm{N}$ $=570, \mathrm{M}=2.74, \mathrm{SD}=0.74$ ).

When students were asked if they would deliberately try to join mixed groups, home students (before $\mathrm{N}=145, \mathrm{M}=2.41, \mathrm{SD}=0.67$; after $N=109, M=2.44, S D=0.71$ ) were less likely to deliberately seek out mixed groups in which to work than international students (before $\mathrm{N}=45, \mathrm{M}=3.04, \mathrm{SD}=0.47$; after $\mathrm{N}=$ 43, $M=2.95, S D=0.57$ ). However, when students were asked how the group setting process should be approached, home and international students all agreed that forcing mixed group working should be avoided (home students before $(\mathrm{N}=145, \mathrm{M}=2.92, \mathrm{SD}=0.68)$ after $(\mathrm{N}=116, \mathrm{M}=2.81, \mathrm{SD}=0.81)$, international students before $(N=41, M=2.76$, $\mathrm{SD}=0.69)$ after $(\mathrm{N}=42, \mathrm{M}=2.74, \mathrm{SD}=0.69))$ and encouraging mixed group work is beneficial (home students before $(N=138, M$ $=2.82, \mathrm{SD}=0.63)$ after $(\mathrm{N}=115, \mathrm{M}=2.88, \mathrm{SD}$
$=0.69)$, international students before $(\mathrm{N}=42$, $M=2.90, S D=0.61)$ after $(N=41, M=2.93$, $\mathrm{SD}=0.59)$ ). Generally, both home and international students agreed that working in mixed groups would be beneficial, with international students more likely to try to join mixed groups than home students when not mixed by the tutors. International students were, overall, also more positive about mixed group work, either set by the tutor or selfselected, than home students.

\section{General group work skills from the SAGA questionnaire}

Interpersonal skills. When asked about the potential for conflict, arguments, or problems getting along with other group members during the group work, all students agreed that this was unlikely to be a problem, and they agreed that the groups were unlikely to have conflict, arguments, or problems getting along. Before the group work international students were more concerned about potential problems $(\mathrm{N}=$ $131, M=2.49, S D=0.67$ ) than home students $(\mathrm{N}=435, \mathrm{M}=2.91, \mathrm{SD}=0.55)$. However, after the group work both international students $(\mathrm{N}=$ $127, M=2.85, S D=0.62)$ and home students $(\mathrm{N}=356, \mathrm{M}=3.30, \mathrm{SD}=0.64$ ) were more in agreement that conflict or arguments were much less than they had expected. International students $(N=83, M=2.87, S D=$ $0.55)$ and home students $(\mathrm{N}=2.75, \mathrm{M}=2.87$, $\mathrm{SD}=0.47$ ) both agreed their group work was likely to be inclusive and they would be able to express their views. Following the group work, both international students $(\mathrm{N}=83, \mathrm{M}=2.90$, $\mathrm{SD}=0.65)$ and home students $(\mathrm{N}=230, \mathrm{M}=$ $3.03, S D=0.65$ ) were more positive about the experience.

Affect. When asked if they were happy and excited to work in a group on the assignment, although home students were more positive about how they viewed the emotional aspects of group work, both international students ( $\mathrm{N}=$ 216, $M=2.82, S D=0.67$ ) and home students $(N=730, M=2.90, S D=0.64)$ agreed that it would be beneficial. After the group work both international students $(N=215, M=2.86, S D$ $=0.71)$ and home students $(\mathrm{N}=587, \mathrm{M}=2.95$, $\mathrm{SD}=0.77$ ) were more strongly agreed that they were happy and excited to work in groups for the assignment. 
Motivational influence. Both home and international students agreed that the group work is motivational. The home students felt that this would be the case, although their viewpoints did not significantly change after the activity (before $\mathrm{N}=296, \mathrm{M}=2.77, \mathrm{SD}=0.55$ and after $\mathrm{N}=235, \mathrm{M}=2.78, \mathrm{SD}=0.71$ ). However, although the international students were agreed that it would be motivational they were less positive after the group work (before $\mathrm{N}=89, \mathrm{M}=2.89, \mathrm{SD}=0.55$ and after $\mathrm{N}=87$, $M=2.78, S D=0.62)$. However, when asked if working as a group would help them to stay motivated and contribute to the assignment, both international students $(\mathrm{N}=89, \mathrm{M}=2.72$, $\mathrm{SD}=0.60)$ and home students $(\mathrm{N}=295, \mathrm{M}=$ 2.70, $\mathrm{SD}=0.58$ ) agreed that this would happen. Following the group work assignment, both international students $(\mathrm{N}=85, \mathrm{M}=2.82$, $\mathrm{SD}=0.62)$ and home students $(\mathrm{N}=230, \mathrm{M}=$ 2.82, $S D=0.71$ ) were more strongly in agreement.

Management. Both international students and home students believe that management of the group assignments will not be a problem, that all group members will be able to make a useful contribution, and that they will be able communicate effectively to reach a consensus. Before the group work activities, the mean responses of international students $(N=216$, $\mathrm{M}=2.59, \mathrm{SD}=0.62)$ and home students $(\mathrm{N}=$ $719, \mathrm{M}=2.69, \mathrm{SD}=0.64$ ) showed that, although they were largely in agreement, there were many of the students who were concerned about potential problems with management. However, after the group work the mean of the responses of both international students $(N=211, M=2.83, S D=0.67)$ and home students $(N=585, M=2.92, S D=0.72)$ identified that a greater number of students were much more positive about the management of the group members during the assignment.

Cognitive benefits. When asked if the group work would enhance their understanding of the subject, and provide an opportunity to learn from others, both international students $(\mathrm{N}=$ $221, M=3.03, S D=0.47$ ) and home students $(\mathrm{N}=738, \mathrm{M}=2.93, \mathrm{SD}=0.48)$ agreed that the group work would provide this benefit and that the group assignments will enrich their understanding of the subject. However, although after the group work both international students $(\mathrm{N}=214, \mathrm{M}=2.94$, SD $=0.60)$ and home students $(\mathrm{N}=591, \mathrm{M}=2.86$, $\mathrm{SD}=0.69$ ) still agreed that there was a benefit, this was less positive.

Group assessment. When asked if the assignment should have been assessed as a group, both international students $(\mathrm{N}=216, \mathrm{M}$ $=2.69, \mathrm{SD}=0.68)$ and home students $(\mathrm{N}=$ $726, \mathrm{M}=2.87, \mathrm{SD}=0.63$ ) agreed. However, after the group work activity international students $(\mathrm{N}=214, \mathrm{M}=2.67, \mathrm{SD}=0.69)$ were unchanged in their responses, but home students $(\mathrm{N}=588, \mathrm{M}=2.96, \mathrm{SD}=0.68)$ were more positive.

\section{Discussion}

Our research showed that home and international students agreed that tutors should deliberately assign them to culturally mixed groups. This is an encouraging finding and may support enhancing student integration by expanding the use of multi-cultural group work to other modules. However, it does still leave the questions of why home and international students see group work differently, and why the student's attitudes changed during the group work activities.

Although both cohorts of students are in agreement, the international students are more strongly in favour of this mechanism for group working than home students. This result is consistent with findings by other authors (De Vita, 2002; Summers \& Volet, 2008; Volet \& Ang, 1998), which has attributed student's attitudes to their previous experience of mixed group work (Summers \& Volet, 2008; Volet \& Ang, 1998). In another study of mixed group work in Australia, home students were concerned about the potentially poor language skills of their international group members from Asia (Kimmel \& Volet, 2012). This was caused by their previous poor experience of mixed group work and led them to prefer to work in non-mixed groups. In this study, the non-native English speakers identified their language skills as average to good, which might mean that the home students' perception of likely problems was not as great as they had originally anticipated resulting in an improved score post-group work. However, this doesn't explain the change in the attitudes of the international students. Potentially these 
findings could be explained by attitudes to other variables associated with group work.

In addition to finding the option for mixed group work more appealing than home students, international students also found the cognitive benefits of group work more favourable too. When the students were asked about the impact of group work on their cognitive skills if they would find the group work beneficial for getting feedback, enhancing understanding of the subject matter, and learning from peers although international and home students agreed that the group work would provide this benefit, international students were more positive about it. Similarly, when asked about motivation in group work, home and international students' responses showed that they agreed they would be more motivated by working with a group of peers, and that they would motivate each other. They also agreed that they would have the opportunity to stay motivated because they were working together and would contribute towards the assignment. Although the international students were slightly less positive that working with a group of peers will help them to stay motivated after the assignment was completed, they did agree that the group work did help them to stay motivated and contribute to the assignment. The outcome of the motivational influence of the group work is in agreement with the previous study (Dolmans \& Schmidt, 2006) which suggests that group work positively affects students' interest in discussing and understanding the subject matter.

Conversely, although international students were more positive about mixed group work than home students, home students have a better overall perception about some other criteria of group work than international students. In particular: the benefits of the emotional aspects of the group work, how they will manage the assignment, the development of interpersonal skills, and group assessment.

The outcome of our research showed a positive emotional response to group work assignments from both international and home students. They agreed that they felt happy to work in the group and excited about the assignment, and were more positive still after the group work. However, the results identified that home students agreed more strongly than the international students about this aspect of group work, contrary to their perception of the mixed group work itself. Integration during group work requires emotional and intellectual participation (De Vita, 2002).

The less positive emotional response of international students to group work assignments compared to the home students could be related to the proportions of home to international students in the groups, or their familiarity with the teaching and learning environment. Future research will aim to investigate these possible issues.

Similarly, both home and international student cohorts believed that management of the group assignments was not a problem, and that all group members were able to make a useful contribution, and that they communicated effectively to reach a consensus, with home students more in favour than international students. All students were initially concerned about finding an effective way of coordinating the work, but after completing the task they largely agreed that this had not been a problem. All group activities in our study were accompanied with clear guidelines for both the procedure and assessment which supports the positive effect of employing clear guidelines and communicating them with students in order to perform successful group work (James et al, 2002).

Both student cohorts were agreed that potential conflict or arguments during the work was unlikely, although international students were more anxious about potential issues than home students. However, after the group work both international students and home students agreed that the possible issues and arguments were less likely than they expected. The students also agreed that the group work activity would be inclusive, and provide an opportunity for them to all express their views, an opinion which was strengthened during the assignment.

International students have been reported as placing more importance on culturalconnectedness, feeling connected with the group and its members, and sharing a similar communication style (Volet \& Ang, 1998). They felt that communication and group 
The relation between multi-cultural group work and the integration of home and international students

management would be better if it was in a common cultural background. This may explain why the international students in this study are more negative about these aspects than home students. They may perceive that finding a common ground and building relationships may be more challenging. However, it is encouraging to see that their response after the assignment was more positive than before the activity.

Both home and international students agreed that group assessment was no problem, and were more strongly in favour when the assignment was completed. The response of home students was more positive than that of the international students and, although all students still agreed that group assessment was not a problem for them, international students were less positive after the assignment was completed whereas the home students were more strongly in favour. This is contrary to previous finding which indicated that home students are more likely to be concerned about poor marks in mixed group work than international students (De Vita, 2002).

Home students are less likely to deliberately seek out mixed groups than international students, and although they are slightly more likely to self-select into mixed groups after the assignment than before it they still show a preference for non-mixed groups. International students, however, were more likely than home students to self-assign themselves to mixed groups, and although they are slightly less likely to do so after the group work they would still choose, on average, a mixed group. The outcome of our research is consistent with the study by Bond and Scudamore (2010) which showed less willingness of home students to mix with other cultures.

Although international students are more likely to have previous experience of studying or working in a different country compared to home students, they are much less likely to regularly socialise with friends from other cultures. This demonstrates that a willingness to study or work internationally does not necessarily impact on social integration. Additional measures to provide opportunities for academic or social integration are required (Kramsch, 2002; Willis \& Sedghi, 2014).
Potential future research could be performed to investigate whether or not international students choose mixed groups to encourage integration, and if there are specific reasons for a greater interest in working in selecting to work in mixed groups from international students.

When setting mixed groups, the students clearly expressed a preference for the way this was approached, and agreed that forcing mixed groups should be avoided, but encouraging them and systematically mixing students was beneficial. We conclude that international students were, overall, more positive about mixed group work in terms of agreeing with, either deliberate assignment by tutors or self-assigning to groups.

Students working in a multi-cultural group find it more difficult to work together and they need more time to adjust themselves and to communicate with each other (Carroll, 2002). Also, the study by Montgomery (2010) indicates that international students can be anxious about mixing with home students. This study identified that many of the perceptions of group work improved during the assignment; interpersonal skills, management, and emotions improved during group work.

\section{Conclusion}

We investigated students' attitudes towards multi-cultural group work from different aspects of interpersonal skills, effect, motivational influence, management and cognitive benefits as well as cultural mix which was the focus of this study.

Although home students were less positive about the cognitive skills and cultural mix benefits of mixed group work than international students, and international students were less positive about interpersonal skills, our overall findings showed students have a positive attitude towards multi-cultural group work. A noteworthy finding in this study is students' agreement that tutors should deliberately assign them to mixed groups rather than expect them to find their own group.

Our study showed that the students' perception of group work could be improved by: clarifying the group work activity; providing a clear 
The relation between multi-cultural group work and the integration of home and international students

introduction to the group work to enhance their understanding of the purpose of the activity and the value of the group work; providing an evaluation tool to identify individual contributions to group work; and a method of identifying areas for improvement.

Potential future research is needed to investigate the effect of language proficiency of international students, the proportions of home to international students in a group, the introduction to the advantages of multi-cultural group work, and the length of assignment on students' appraisal towards the multi-cultural group work.

\section{Acknowledgments}

This work was supported by the Faculty of Science and Engineering, The University of Liverpool Enhancement of Learning and Teaching for large multicultural classes funding scheme (2015-2016). We thank Professor S. E. Volet for kindly allowing us to use her contextualised SAGA instrument. We also thank Gina Washbourn for her assistance with data analysis.

\section{References}

Andrich, David. (1978). Relationships between the Thurstone and Rasch approaches to item scaling. Applied Psychological Measurement, 2, 451-462.

DOI:10.1177/014662167800200319

Baker, R.W. \& Siryk, B. (1999). SACQ Student Adaptation to College Questionnaire. Los Angeles: Los Angeles: Western Psychological Services.

Baohua, Y. \& Huizhong, S. (2012). Predicting roles of linguistic confidence, integrative motivation and second language proficiency on cross-cultural adaptation. International Journal of Intercultural Relations, 36, 72-82. DOI: 10.1016/j.jintrel.2010.12.002

Bentley, Y. \& Warwick, S. (2013). Students' experience and perceptions of group assignments. Paper presented at the HEA STEM Conference, Birmingham.

Bond, K. \& Scudamore, R. (2010). Working with international students: A guide for staff in Engineering. HEA subject centre guide.
British Council. (2012). Student insight - China. Retrieved from British Council website: https://siem. britishcouncil.org/ei-itemdisplay/student-insight-china

British Council. (2015a). Is China creating a workforce with no soft skills? Retrieved from British Council website: https://www.britishcouncil.org/voicesmagazine/china-creating-workforce-no-soft$\underline{\text { skills }}$

British Council. (2015b). Student insight Brazil. Retrieved from British Council website: https://ei.britishcouncil.org/educationintelligen ce/student-insight-brazil-2015

British Council. (2015c). UK is top host of international students, but for how long? Retrieved from British Council website: https://www.britishcouncil.org/voicesmagazine/uk-top-host-international-studentshow-long

Carroll, J. (2002). Suggestions for teaching international students more effectively. Retrieved from Oxford Centre for Staff and Learning Development: learning and teaching briefing paper.

Chickering, A.W. \& Gamson, Z.F. (1989). Seven principles for good practice in undergraduate education. Biochemical Education, 17(3), 140-141.

Chickering, A.W. \& Gamson, Z.F. (1999). Development and Adaptations of the Seven Principles for Good Practice in Undergraduate Education. New Directions for Teaching and Learning, 75-81. DOI: 10.1002/tl.8006.

Coser, L.A. (1975). The idea of social structure: Papers in honor of Robert K. Merton. New York: Harcourt Brace Jovanovich.

De Vita, G. (2002). Does Assessed Multicultural Group Work really pull UK Students' Average down?. Assessment \& Evaluation in Higher Education, 27(2), 153161. DOI: $10.1080 / 02602930220128724$

Dolmans, D.H.J.M. \& Schmidt, H.G. (2006). What Do We Know About Cognitive and Motivational Effects of Small Group Tutorials in Problem-Based Learning? Advances in Health 
The relation between multi-cultural group work and the integration of home and international students

Sciences Education, 11, 321-326. DOI: 10.1007/s10459-006-9012-8

Ennew, C. \& Greenway, D. (2012). The Globalization of Higher Education. Palgrave Macmillan.

Eva, H. \& Roger, S. (2012). Representing diversity in education: Student identities in contexts of learning and instruction. International Journal of Educational Research, 63, 1-4. DOI: 10.1016/j.jijer.2012.10.001

Gurin, P., Dey, E.L., Hurtado, S. \& Gurin, G. (2002). Diversity and higher education: Theory and impact on educational outcomes (English). Diversité et enseignement supérieur: théorie et impact sur les résultats scolaires (French), 72(3), 330-366.

Hardy, J., Bates, S.P., Casey, M.M., Galloway, K.W., Galloway, R.K., Kay, A.E. \& McQueen, H.A. (2014). Student-Generated Content: Enhancing learning through sharing multiplechoice questions. International Journal of Science Education, 36(13), 2180-2194. DOI: 10.1080/09500693.2014.916831

HESA. (2015). The official source of data about UK universities and HE colleges. from Higher Education Statistics Agency

James, R., Mclnnis, C., \& Devlin, M. (2002). Assessing group work. Assessing Learning in Australian Universities.

Jones, E. \& Brown, S. (2007). Internationalising higher education. London: Routledge.

Kimmel, K. \& Volet, S. (2010). Significance of context in university students' (meta)cognitions related to group work: A multi-layered, multidimensional and cultural approach. Learning and Instruction, 20(6), 449-464. DOI: 10.1016/j.learninstruc.2009.05.004

Kimmel, K. \& Volet, S. (2012). University students' perceptions of and attitudes towards culturally diverse group work: Does context matter?. Journal of Studies in International Education, 16(2), 157-181. DOI: $10.1177 / 1028315310373833$
Knight, J. (2004). Internationalization remodelled: Definition, approaches, and rationales. Journal of Studies in ILinkedin1nternational education, 8, 5-31.

Kramsch, C. (2002). In search of the intercultural. Review of Jandt, F. E., Intercultural Communication: An Introduction. 3rd edition.; Young Yun Kim. Becoming Intercultural: An Integrative Theory of Communication And Cross-Cultural Adaptation.; Tony Schirato and Susan Yell. Communication And Culture: An Introduction; Ron Scollon and Suzanne Wong Scollon. Intercultural Communication: A Discourse Approach. 2nd Edition. Journal of Sociolinguistics, 6, 275-285.

Kriflic, L. \& Mullan, J. (2007). Strategies to improve student reaction to group work. Journal of University Teaching \& Learning Practice, 4(1).

Liou-Mark, J., Dreyfuss, A.E. \& Younge, L. (2010). Peer assisted learning workshops in precalculus: an approach to increasing student success. Mathematics \& Computer Education, 44(3), 249-259.

Mannan, M.A. (2007). Student attrition and academic and social integration: Application of Tinto's model at the University of Papua New Guinea. Higher Education, 53(2), 147-165. DOI: 10.1007/s10734-005-2496-y

Marjan, L., \& Seyed Mohammad, G. (2011). Benefits of collaborative learning. Procedia Social and Behavioral Sciences, 31, 486-490. DOI: 10.1016/j.sbspro.2011.12.091

Montgomery, C. (2010). Understanding the international student experience: Palgrave Macmillan.

Nicol, D. (2007). E-assessment by design: using multiple-choice tests to good effect. Journal of Further and Higher Education, 31(1), 53-64.

Popov, V., Brinkman, D., Biemans, H.J.A., Mulder, M., Noroozi, O. \& Kuznetsov, A. (2012). Multicultural student group work in higher education. An explorative case study on challenges as perceived by students. 
The relation between multi-cultural group work and the integration of home and international students

International Journal of Intercultural Relations, 36(2), 302-317.

DOI: 10.1016/j.ijintrel.2011.09.004

Rienties, B., Beausaert, S., Grohnert, T., Niemantsverdriet, S., \& Kommers, P. (2012). Understanding academic performance of international students: The role of ethnicity, academic and social integration. Higher Education, 63(6), 685-700. DOI: 10.1007/s10734-011-9468-1

Summers, M., \& Volet, S. (2008). Students' attitudes towards culturally mixed groups on international campuses: Impact of participation in diverse and non-diverse groups. Studies in Higher Education, 33(4), 357-370. DOI: $10.1080 / 03075070802211430$

Summers, M., \& Volet, S. (2010). Group work does not necessarily equal collaborative learning: evidence from observations and selfreports, 473.

Tinto, V. (1975). Dropout from Higher Education: A Theoretical Synthesis of Recent Research. Review of Educational Research, 45(1), 89-125.

UKCISA. (2015). International students statistics

Umans, T. (2011). Globalisation in the lecture room? Gender and cultural diversity in work groups. Issues in Educational Research, 21(1), 88-103.

UUK. (2014). International students in higher education: The UK and its competition. Retrieved from:

http://www.universitiesuk.ac.uk/policy-andanalysis/reports/Documents/2014/internationa l-students-in-higher-education.pdf

Vitaliy, P., Dine, B., Harm, J. A. B., Martin, M., Andrei, K., \& Omid, N. (2012). Multicultural student group work in higher education. An explorative case study on challenges as perceived by students. International Journal of Intercultural Relations, 36, 302-317. DOI: 10.1016/j.jintrel.2011.09.004

Volet, S. (2001). Student motivation: The culture and context of learning: Springer US.
Volet, S. E., \& Ang, G. (1998). Culturally mixed groups in international campuses: $A n$ opportunity for intercultural leaning. Higher Education Research and Development, 17(1), 5-23.

Watson, W. E., Johnson, L., Kumar, K., \& Critelli, J. (1998). Process gain and process loss: Comparing interpersonal processes and performance of culturally diverse and nondiverse teams across time. International Journal of Intercultural Relations, 22(4), 409430.

Willis, I., \& Sedghi, G. (2014). Perceptions and experiences of home students involved in welcoming and supporting direct entry 2nd year international students. Practice and Evidence of Scholarship of Teaching and Learning in Higher Education, 9(1), 2-17.

Wosnitza, M., \& Volet, S. (2009). Interface of personal content goals with social direction and motivational patterns in collaborative learning contexts. Paper presented at the EARLIConference, Amsterdam.

Wosnitza, M., \& Volet, S. (2012). Group heterogeneity and homogeneity in personal content goals for a group learning activity: Impact on individual appraisals. Applied Psychology: An International Review, 61(4), 585-604. DOI: 10.1111/j.14640597.2012.00507.x 